\title{
Safety and feasibility study of using polyphosphate (PolyP) in alveolar cleft repair: a pilot study
}

Salem A. Alkaabi ${ }^{1,2^{*}+}$, Diandra Sabrina Natsir Kalla ${ }^{1,3+}$, Ghamdan A. Alsabri ${ }^{1}$, Abul Fauzi ${ }^{4}$, Nova Jansen ${ }^{1}$, Andi Tajrin ${ }^{4}$, Rifaat Nurrahma ${ }^{1,7}$, Werner Müller ${ }^{5,6}$, Heinz C. Schröder ${ }^{5,6}$, Wang Xiaohong ${ }^{5,6}$, Tymour Forouzanfar ${ }^{1,4}$, Marco N. Helder ${ }^{1,4}$ and Muhammad Ruslin ${ }^{4^{*}}$

\begin{abstract}
Background: Bone grafting is an important surgical procedure to reconstruct alveolar bone defects in patients with cleft lip and palate. Polyphosphate (PolyP) is a physiological polymer present in the blood, primarily in platelets. PolyP plays a role as a phosphate source in bone calcium phosphate deposition. Moreover, the cleavage of high-energy bonds to release phosphates provides local energy necessary for regenerative processes. In this study, polyP is complexed with calcium to form Calcium polyP microparticles (Ca-polyP MPs), which were shown to have osteoinductive properties in preclinical studies. The aim of this study was to evaluate the feasibility, safety, and osteoinductivity of Ca-polyP MPs, alone or in combination with BCP, in a first-in-human clinical trial.
\end{abstract}

Methods: This single-blinded, parallel, prospective clinical pilot study enrolled eight adolescent patients (mean age 18.1: range 13-34 years) with residual alveolar bone cleft. Randomization in two groups (four receiving Ca-polyP MPs only, four a combination of Ca-polyP MPs and biphasic calcium phosphate (BCP)) was performed. Patient follow-up was 6 months. Outcome parameters included safety parameters and close monitoring of possible adverse effects using radiographic imaging, regular blood tests, and physical examinations. Osteoinductivity evaluation using histomorphometric analysis of biopsies was not possible due to COVID restrictions.

Results: Due to surgical and feasibility reasons, eventually, only 2 patients received Ca-polyP MPs, and the others the combination graft. All patients were assessed up to day 90 . Four out of eight were able to continue with the final assessment day (day 180). Three out of eight were unable to reach the hospital due to COVID-19 restrictions. One patient decided not to continue with the study.

None of the patients showed any allergic reactions or any remarkable local or systematic side effects. Radiographically, patients receiving Ca-polyP MPs only were scored grade IV Bergland scale, while patients who got the BCP/CapolyP MPs combination had scores ranging from I to III.

\footnotetext{
*Correspondence: al_kaabi33@hotmail.com; mruslin@unhas.ac.id

†Salem A. Alkaabi and Diandra Sabrina Natsir Kalla shared first authorship.

2 Department of Oral and Maxillofacial Surgery, Fujairah Hospital, Ministry

of Health, Fujairah, United Arab Emirates

${ }^{4}$ Department of Oral and Maxillofacial Surgery, Faculty of Dentistry,

Hasanuddin University, Makassar, Indonesia

Full list of author information is available at the end of the article
}



(c) The Author(s) 2021. Open Access This article is licensed under a Creative Commons Attribution 4.0 International License, which permits use, sharing, adaptation, distribution and reproduction in any medium or format, as long as you give appropriate credit to the original author(s) and the source, provide a link to the Creative Commons licence, and indicate if changes were made. The images or other third party material in this article are included in the article's Creative Commons licence, unless indicated otherwise in a credit line to the material. If material is not included in the article's Creative Commons licence and your intended use is not permitted by statutory regulation or exceeds the permitted use, you will need to obtain permission directly from the copyright holder. To view a copy of this licence, visit http://creativecommons.org/licenses/by/4.0/. The Creative Commons Public Domain Dedication waiver (http://creativeco mmons.org/publicdomain/zero/1.0/) applies to the data made available in this article, unless otherwise stated in a credit line to the data. 
Conclusions: Our results indicate that Ca-polyP MPs and the BCP/Ca-polyP MPs combination appear to be safe graft materials; however, in the current setting, Ca-polyP MPs alone may not be a sufficiently stable defect-filling scaffold to be used in alveolar cleft repair.

Trial registration: Indonesian Trial Registry under number INA-EW74C1N by the ethical committee of Faculty of Medicine, Hasanuddin University, Makassar, Indonesia with code number 1063/UN4.6.4.5.31/PP36/2019.

Keywords: Polyphosphate, Alveolar bone grafting, Bone regeneration, Regenerative medicine

\section{Introduction}

\section{Background}

Cleft lip and palate (CLP) are common anomalies in the craniofacial region and are considered the second most common congenital deformity after the clubfoot [1]. An alveolar cleft is seen in $75 \%$ of the CLP patients $[2,3]$. Alveolar bone grafting (ABG) is an essential functional and esthetic procedure to reconstruct the bony defect in the maxilla as well as the nasal floor [4]. ABG not only plays an important role to facilitate teeth eruption, but also to fill the bony defect by closing the oronasal fistula that routinely occurs in alveolar cleft patients.

The alveolar bone grafting can be performed using autogenous bone, allograft bone, or bone substitutes. Autogenous bone graft is still considered as the gold standard for any grafting procedure [5]; nevertheless, numerous studies are employing various bone substitutes or allografts to overcome the risks and complications that could raise from harvesting bone at the donor site [6-8]. Risks such as gait disturbance, hematoma, donor site morbidity, and other concerns that are associated with the growth (through harvesting from the rib or the iliac crest) could be avoided if a good allograft or bone substitute material would be available [9].

Polyphosphate (polyP) is a molecule that is naturally present in platelets in the blood stream. Müller and his colleagues have been able to structure a new graft material by precipitation of polyP with calcium, thus forming Ca-polyP microparticles (Ca-polyP MPs) [10-12]. The Ca-polyP MPs were proven to have bone osteoinductive characteristics in preclinical studies [12-14]. It has been shown that the Ca-polyP MPs can accumulate and concentrate at the site of the new bone formation. PolyP polymer elicits both the anabolic signals and the fuel due to energy-rich phosphate anhydrides linkages as well as the metabolic process in the cells. Such signals could accelerate the cell growth and differentiation [15].

On the other hand, Biphasic calcium phosphate (BCP) is another type of graft that contains a phosphate molecule mixed with hydroxyapatite (HA) in different ratios. Ambivalent outcomes have been reported to BCP as graft material; some stated that $\mathrm{BCP}$ has osteoconductive characteristics $[16,17]$, while others concluded that it also can be osteoinductive in nature $[18,19]$.

\section{Objective}

This first-in-human study aims to evaluate the safety, feasibility, and osteoinductivity of Ca-polyP MPs, alone or in combination with $\mathrm{BCP}$, as a graft material in alveolar cleft patients.

\section{Material and methods \\ Ethics}

This single-blinded, prospective clinical trial, a pilot study was approved by the ethical committee of Faculty of Medicine, Hasanuddin University, Makassar, Indonesia, with code number 1063/UN4.6.4.5.31/PP36/2019. It was registered in the Indonesian Trial Registry under number INA-EW74C1N. The study protocol complies with the principles of the Helsinki declaration. Patients and legal guardians of the patients signed an informed consent.

No special ethical approval was required for this study.

\section{Patients and randomization}

This study enrolled eight patients with residual alveolar bone cleft. The inclusion criteria were non-syndromic, nonsmoker, age of $\geq 13$, no history of previous grafting procedure(s), and ASA1 regarding anesthetic risks. The exclusion criteria were systemic diseases, syndromic patients, localized infection, active influenza, obvious malnutrition, or patient under any active medical treatment. Randomly using closed envelopes, four out of eight patients were selected to receive the Ca-polyP MPs alone, while the other four patients were to receive a mixture of Ca-polyP MPs and BCP as a graft material. However (see the "Results" section), eventually, two patients only received Ca-polyP MPs alone, while six received the mixture. The surgeon and the patients were revealed to the graft type; nevertheless, the assessor was kept completely blinded from the patient grouping. The time schedule of the surgical procedure and follow-up moments is presented in Table 1.

\section{Sample size}

Since this is a first-in-human trial, the number of patients was kept low in order to minimize the risk of the graft exposure in case of any adverse effect. The current trial 
Table 1 Treatment time schedule

\begin{tabular}{|c|c|c|c|c|c|c|c|}
\hline & Consent form & Panorama & CBCT or CT & $\begin{array}{l}\text { Physical } \\
\text { examination }\end{array}$ & $\mathrm{CBC}$ & Thermometer & Biopsy \\
\hline Preoperatively & $\checkmark$ & $\checkmark$ & $\checkmark$ & $\checkmark$ & $\checkmark$ & $\checkmark$ & \\
\hline Operative day & & & & $\checkmark$ & & $\checkmark$ & \\
\hline Post-op day 1 & & $\checkmark$ & & $\checkmark$ & $\checkmark$ & $\checkmark$ & \\
\hline Post-op day 8 & & $\checkmark$ & $\checkmark$ & $\checkmark$ & $\checkmark$ & $\checkmark$ & \\
\hline Post-op day 14 & & & & $\checkmark$ & & $\checkmark$ & \\
\hline Post-op day 30 & & & & $\checkmark$ & $\checkmark$ & $\checkmark$ & \\
\hline Post-op day 90 & & $\checkmark$ & & $\checkmark$ & & $\checkmark$ & \\
\hline Post-op day 180 & & $\checkmark$ & $\checkmark$ & $\checkmark$ & $\checkmark$ & $\checkmark$ & $\checkmark$ \\
\hline
\end{tabular}

OPG orthopantomogram, $C T$ computed tomography, $C B C T$ cone beam CT

sample was limited to only $2 \times 4$ patients, with the primary goal to gain a first insight on the feasibility and safety of the treatment with polyP.

\section{Randomization and treatment allocation}

After written informed consent, randomization was performed with regard to the treatment group, but all patients were aware of the fact that their treatment comprised Ca-polyP MPs.

\section{Blinding}

The radiologist remained blind to the treatment when evaluating the data.

\section{Data collection}

Doctors, nurses, and the rest of the research team were provided with a list of rules and responsibilities. The doctors and nurses collected the data according to the assessment Table 1. All research team members received training on how to collect data at all study visits. Each patient has been followed up to 6 months. Patient confidentiality was protected by the data manager.

\section{Polyp and BCP preparation}

PolyP graft comes in a form of Ca-polyP MPs powder produced by NanotecMARIN GmbH (Mainz, Germany), while the BCP consists of a mixture of $60 \%$ hydroxyapatite and $40 \%$ of beta-tricalcium phosphate (Straumann Bone Ceramic, Villeret, Switzerland). Under sterile conditions, either Ca-polyP MPs or a mixture of Ca-polyP MPs and $\mathrm{BCP}$ was prepared using normal saline at a ratio of $1 \mathrm{~g}: 1.5 \mathrm{ml}$ and $1 \mathrm{~g}: 2 \mathrm{~g}: 3-5 \mathrm{ml}$ respectively. The components were mixed until a homogenous mixture was obtained (Fig. 1).

\section{Surgical procedure}

Under general anesthesia and full aseptic conditions, the oral cavity was rinsed with $0.1 \%$ chlorhexidine gluconate

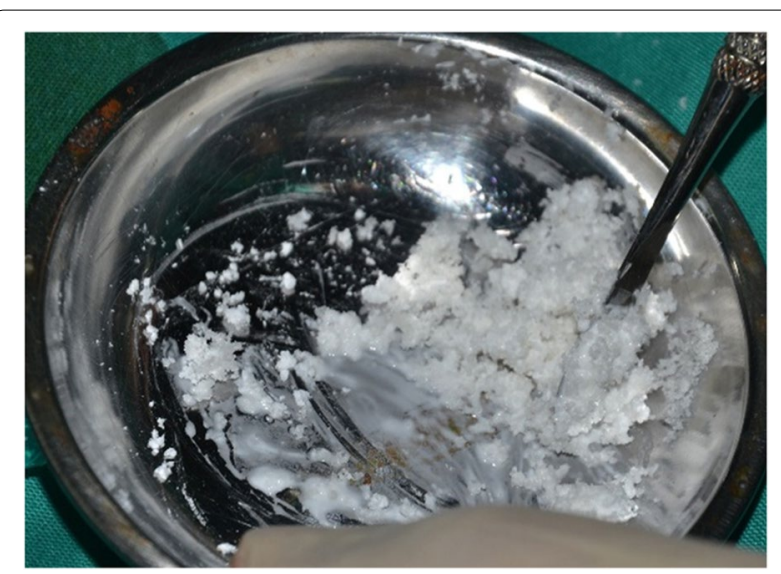

Fig. 1 Ca-polyP MP + BCP mixed with normal saline

solution. A local anesthesia infiltration using lidocaine with epinephrine 1:100,000 was given. Full mucoperiosteal flap was reflected from the first molar to the central incisor on the contralateral side of the defect. The tissue was dissected carefully to separate the oral mucosa from the nasal layer. A palatal mucoperiosteal flap was reflected from either side of the cleft followed by elevation of the palatal tissues. The nasal mucosa was cranially elevated and sutured cranially to repair the oro-nasal fistula (Fig. 2a). A Ca-polyP MPs preparation or the CapolyP MPs and BCP mixture was applied into the alveolar cleft defect (Fig. 2b). Tension-free closure was realized in all wounds.

\section{Postoperative care}

Oral hygiene instructions were given to all patients including mouth rinsing with $0.12 \%$ Chlorhexidine. Antibiotics (amoxicillin/clavulanic acid) and pain killers were prescribed for 7 days according to the standard of care. During hospital stay, follow-up examinations of all patients were meticulously performed to report any adverse reaction to the grafting materials locally or 


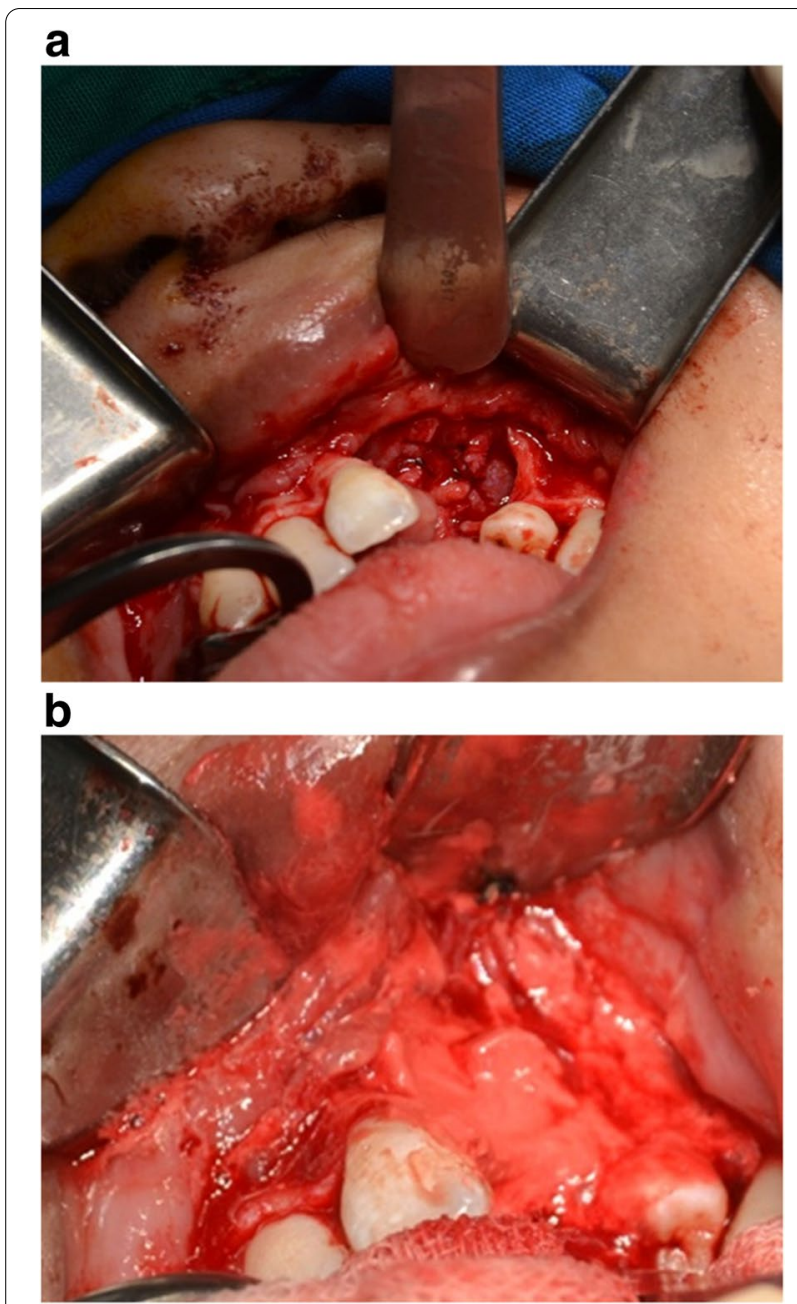

Fig. 2 a Nasal floor reconstruction and exposing the bony edges. $\mathbf{b}$ Ca-polyP MPs graft placed in the defect systemically. After patient discharge, all patients followed an assessment timetable.

\section{Orthopantomogram (OPG) \\ Bergland scale}

OPGs were taken one day preoperatively (X-Mind Pano D+ Satelec- Digital panoramic with teleradiography Satelec), and then subsequently after 8, 30, 90, and 180 days. The OPGs were used to assess the vertical graft formation employing the Bergland scale, which is the gold standard used to evaluate the integrity and height of the alveolar bone graft [20]. The Bergland scale is classified into four grades: grade I, bone height is almost a normal height; grade II, a bone height at least $75 \%$ of the interalveolar septum; grade III, the bone height is less than $75 \%$; and grade IV, no evidence of bone integration [21].

\section{CT scan}

The CT scans (Siemens SOMATOM Definition Flash CT Scanner) were performed preoperatively and at postoperative days 8 and 180. The data were processed by OsiriX (Pixmeo, Switzerland), an open-source Digital Imaging and Communications in Medicine (DICOM).

\section{Results}

All patients were able to comply with the study requirements up to assessment day 90 . Unfortunately, four out of eight patients were unable to continue with the final assessment (day 180). One patient decided not to continue with the study, while the other three patients were unable to approach the hospital due to the COVID-19 lockdown at their towns/villages (Table 2).

All eight patients underwent bone grafting surgery by the same surgeon. There were no reported postoperative complications, local or systematic, in both study groups. All patients were in close follow-up from day 1 until they were discharged from the hospital (day 3). Thereafter,

Table 2 Demographic and assessment data

\begin{tabular}{|c|c|c|c|c|c|c|c|c|}
\hline & Pt.1 & Pt.2 & Pt.3 & Pt.4 & Pt.5 & Pt.6 & Pt.7 & Pt.8 \\
\hline Gender & $F$ & $\mathrm{~F}$ & $M$ & $\mathrm{~F}$ & $F$ & $F$ & $F$ & $\mathrm{~F}$ \\
\hline Age & 18 & $13 / 14$ & 13 & 15 & 13 & 15 & 24 & 34 \\
\hline Affected side & Left & Left & Bilateral & Left & Right & Left & Right & Left \\
\hline Graft type & Ca-polyP MPs & Ca-polyP MPs & $\begin{array}{l}\text { Ca-polyP MPs } \\
+B C P\end{array}$ & $\begin{array}{l}\text { Ca-polyP MPs } \\
+B C P\end{array}$ & $\begin{array}{l}\text { Ca-polyP MPs } \\
+ \text { BCP }\end{array}$ & $\begin{array}{l}\text { Ca-polyP MPs } \\
+ \text { BCP }\end{array}$ & $\begin{array}{l}\text { Ca-polyP MPs } \\
+B C P\end{array}$ & $\begin{array}{l}\text { Ca-polyP MPs } \\
+ \text { BCP }\end{array}$ \\
\hline $\begin{array}{l}\text { Assessment } \\
\text { day } 30\end{array}$ & Completed & Completed & Completed & Completed & Completed & Completed & Completed & Completed \\
\hline $\begin{array}{l}\text { Assessment } \\
\text { day } 90\end{array}$ & Completed & Completed & Completed & Completed & Completed & Completed & Completed & Completed \\
\hline $\begin{array}{l}\text { Assessment } \\
\text { day } 180\end{array}$ & $\begin{array}{l}\text { Missed follow- } \\
\text { up, COVID-19 } \\
\text { lockdown }\end{array}$ & Completed & Completed & Completed & $\begin{array}{l}\text { Missed follow- } \\
\text { up, COVID-19 } \\
\text { lockdown }\end{array}$ & $\begin{array}{l}\text { Missed follow- } \\
\text { up, COVID-19 } \\
\text { lockdown }\end{array}$ & Drop-out & Completed \\
\hline
\end{tabular}

$P t$. patient, $F$ female, $M$ male, $C a-p o l y P$ calcium polyphosphate microparticles, $B C P$ biphasic calcium phosphate 
the patients were followed up according to Table 2 . Although not included in the initial trial design, all patients were contacted with video or telephone calls up for a 1-year follow-up. No adverse events were reported, and all patients reported that they were content with the treatment.

\section{Feasibility}

Two different application modes of Ca-polyP-MP should have been tested in a randomized manner, but as a consequence of the difficulty to handle Ca-polyP microparticles when not complexed with $\mathrm{BCP}$, we had to abandon the randomization of graft type and applied the BCPpolyP graft type only. Thus, feasibility appeared valid for the combination graft, but not (in the current setting) for the application of Ca-polyP MPs only.

\section{Safety}

\section{Adverse events}

The main goal of this study was to evaluate the safety of the Ca-polyP MPs, alone or in combination with $\mathrm{BCP}$, in terms of adverse events (local or systemic) using clinical assessment, radiographic, and laboratory investigations (a.o. white blood cells, neutrophil, lymphocyte, and if needed C-reactive protein) (Table 3). All patients were kept hospitalized postoperatively for $72 \mathrm{~h}$ to maintain close follow-up. In the case of SAE concerning severe toxicity or infection associated with the graft site, the trial would be terminated immediately.

\section{Osteoinductivity}

Since the acquirement of biopsies was not possible due to COVID-19 restrictions, this aspect could not be evaluated as planned [22].

\section{Radiographic evaluation} Orthopantomogram

The Bergland scale was used in this study to investigate the result of the secondary bone grafts in alveolar defects. This scale is considered the gold standard to assess the post alveolar graft height of the interdental septum. Although OPG is more susceptible to distortions, it was chosen because it is more patient-friendly when compared to the other intra-oral $\mathrm{x}$-rays, especially when taken postoperatively.

In the Ca-polyP MPs group (patients 1 and 2), bone levels were not suitable to be analyzed with the Bergland scale, and we decided to score them as grade IV bone level at all assessment days (Table 4). One of these patients could not attend the last follow-up session (day 180). In the Ca-polyP MPs-BCP group, the bone level ranged from grade I to III in assessment days 1,8 , and 90. Only three patients could be assessed at day 180 , and all of them had grade III bone level (Table 4).

\section{CT scan evaluation}

As indicated above, the bone levels in the Ca-polyP MPs group could not be analyzed with the Bergland scale. The material had a ground glass appearance (scattered light radiopaque). Since no bone level could be identified we classified them as grade IV at both day 8 and day 180. In the Ca-polyP MPs-BCP group, the $\mathrm{CT}$ scans showed a differential bone level from grade I to grade III per patient (Table 5). For the last three patients who could be scanned at day 180 , bone levels were found to be consistent with those determined with the OPG, i.e., grade III Bergland scale.

Table 3 Safety assessments

\begin{tabular}{|c|c|c|c|c|c|c|c|c|}
\hline & Pt.1 & Pt.2 & Pt.3 & Pt.4 & Pt.5 & Pt.6 & Pt.7 & Pt.8 \\
\hline Graft type & Ca-polyP MPs & Ca-polyP MPs & $\begin{array}{l}\text { Ca-polyP MPs } \\
+ \text { BCP }\end{array}$ & $\begin{array}{l}\text { Ca-polyP MPs } \\
+ \text { BCP }\end{array}$ & $\begin{array}{l}\text { Ca-polyP MPs } \\
+ \text { BCP }\end{array}$ & $\begin{array}{l}\text { Ca-polyP MPs } \\
+ \text { BCP }\end{array}$ & $\begin{array}{l}\text { Ca-polyP MPs } \\
+ \text { BCP }\end{array}$ & $\begin{array}{l}\text { Ca-polyP MPs } \\
+ \text { BCP }\end{array}$ \\
\hline Pain & Mild & Mild & $\begin{array}{l}\text { Minimum } \\
\text { pain/pressure }\end{array}$ & Mild & Mild & $\begin{array}{l}\text { Minimum } \\
\text { pain/pressure }\end{array}$ & Mild & Moderate \\
\hline Fever & No & No & No & No & No & No & No & No \\
\hline $\begin{array}{l}\text { Allergic reac- } \\
\text { tion }\end{array}$ & ND & ND & ND & ND & ND & ND & ND & ND \\
\hline $\begin{array}{l}\text { Remarkable } \\
\text { local inflam- } \\
\text { mation/infec- } \\
\text { tion }\end{array}$ & No & No & No & No & No & No & No & No \\
\hline $\begin{array}{l}\text { Systematic } \\
\text { adverse effect }\end{array}$ & ND & ND & ND & ND & ND & ND & ND & ND \\
\hline Lab tests & $\begin{array}{l}\text { Within normal } \\
\text { limits }\end{array}$ & $\begin{array}{l}\text { Within normal } \\
\text { limits }\end{array}$ & $\begin{array}{l}\text { Within normal } \\
\text { limits }\end{array}$ & $\begin{array}{l}\text { Within normal } \\
\text { limits }\end{array}$ & $\begin{array}{l}\text { Within normal } \\
\text { limits }\end{array}$ & $\begin{array}{l}\text { Within normal } \\
\text { limits }\end{array}$ & $\begin{array}{l}\text { Within normal } \\
\text { limits }\end{array}$ & $\begin{array}{l}\text { Within normal } \\
\text { limits }\end{array}$ \\
\hline
\end{tabular}

Ca-polyP MPs calcium polyphosphate microparticles, $B C P$ biphasic calcium phosphate, $N D$ nothing detected 
Table 4 Bergland scores based on OPGs

\begin{tabular}{|c|c|c|c|c|c|c|c|c|}
\hline \multirow[t]{2}{*}{ Bergland scale } & \multicolumn{2}{|c|}{ Ca-Polyp MPs graft } & \multicolumn{6}{|c|}{ Ca-Polyp MPs + BCP } \\
\hline & Pt.1 & Pt.2 & Pt.3 & Pt.4 & Pt.5 & Pt.6 & Pt.7 & Pt.8 \\
\hline Day 1 & IV & IV & । & । & $\|$ & I & I & । \\
\hline Day 8 & IV & IV & I & । & $\|$ & I & I & I \\
\hline Day 90 & IV & IV & III & III & III & III & $\|$ & III \\
\hline Day 180 & ND & IV & III & III & ND & ND & ND & III \\
\hline
\end{tabular}

ND no data

Table 5 Bergland scores based on CTs scan

\begin{tabular}{|c|c|c|c|c|c|c|c|c|}
\hline \multirow[t]{2}{*}{ Bergland scale } & \multicolumn{2}{|l|}{ Ca-polyP MPs graft } & \multicolumn{6}{|c|}{ Ca-polyP MPs + BCP } \\
\hline & Pt.1 & Pt.2 & Pt.3 & Pt.4 & Pt.5 & Pt.6 & Pt.7 & Pt.8 \\
\hline Day 8 & IV & IV & । & $\|$ & I & III & । & $\|$ \\
\hline Day 180 & $\begin{array}{l}\text { Missed follow-up, } \\
\text { COVID-19 lockdown }\end{array}$ & IV & III & III & $\begin{array}{l}\text { Missed follow-up, } \\
\text { COVID-19 lockdown }\end{array}$ & $\begin{array}{l}\text { Missed follow-up, } \\
\text { COVID-19 lockdown }\end{array}$ & Drop-out & III \\
\hline
\end{tabular}

a-polyP MPs calcium polyphosphate microparticles, $B C P$ biphasic calcium phosphate

\section{Complications}

There were no complications reported intra- and/or postoperatively in both study groups.

\section{Discussion}

In the current trial, we found that Ca-polyP MPs appear to be a safe material: no unusual adverse reactions were reported, such as infection, severe pain, swelling, allergic reaction, or any other local or systemic adverse effects. With regard to the feasibility, the microparticles probably may need a stable graft material such as BCP for appropriate alveolar reconstruction.

The optimum age for the alveolar bone grafting is considered to be between 9 and 11 years old [20, 23]. Since we did not want to enroll children in a safety study with this novel material in clinical practice, we chose to only include older adolescent and adult patients, being capable themselves to make sound decisions. We performed this study in Indonesia because non-operated patients in this age group are difficult to find in Europe.

In the Ca-polyP MPs group, the main challenge was in the handling and application of the material in the alveolar defect. The characteristics of the Ca-polyP MPs can be determined by $\mathrm{Pi}$ : $\mathrm{Ca}+2$ molar ratio. In our trial, we used a paste-like mixture formed by mixing fine Ca-polyP MPs graft with normal saline as described in the materials and methods. However, the resulting $\mathrm{Ca}$ polyP MPs graft material was easily lost from the surgical sites once it got saturated with blood, which made maintaining a space-occupying scaffold within the alveolar defect virtually impossible. We therefore had to conclude that the physical characteristics of the $\mathrm{Ca}$ polyP MPs used as a stand-alone scaffold material were insufficient and unfeasible. As a consequence, we had to reduce the Ca-polyP MPs only group to 2 instead of 4 patients as planned originally in the study protocol. Retrospectively, the reason that the microparticles were previously shown to be effective in bone formation in preclinical studies may be due to the location used: it was implanted in a subcutaneous pocket instead of a not well contained, large void such as the alveolar cleft $[24,25]$.

Combining the Ca-polyP MPs with BCP considerably improved the consistency, ease of handling, stability of the graft, and clinical outcome. BCP and calcium phosphates in general have been used as a graft material several times in craniofacial surgery before. For example, Levitt et al. already used calcium phosphate in 1969 for this purpose, and calcium phosphates were subsequently used in dental implant, alveolar ridge augmentation, periodontal treatment, and other maxillofacial surgeries. Biphasic calcium phosphate (BCP) has been proven to be biocompatible and exhibit osteoconductive as well as osteoinductive characteristics in bony defects reconstruction $[16,17,19]$. Calcium phosphate was also recently applied in alveolar cleft surgery [26]. Based on our results, we recommend that to achieve the feasibility of applying bioactive Ca-polyP MP, it should be combined with a stable carrier such as BCP or bioresorbable polymers to ensure proper reconstructive activity. Likely, special attention should be paid to 
sequestration of the polyP on or within the carrier, of which we could not be sure in the current study.

Our study was limited by several aspects, the most severe being the COVID-19 pandemic allowing only 4 patients to be evaluated after 180 days of follow-up and thereby resulting in a rather short postoperative follow-up period. Another limitation was the rather radiolucent characteristic of the Ca-polyP MPs, which hampered visualization of the graft in radiographic images considerably and making an evaluation with the Bergland scale virtually impossible. We also tried the Chelsea scale [27], which analyzes the bone position in relation to the adjacent teeth on the grafting site radiographically. However, this did not result in other outcomes as the Bergland scale, so we omitted these results. We can therefore not be completely sure whether defect filling was sufficient and if some initial bone regeneration events occurred, but at least no solid bone formation was demonstrated after 3 months, and also not in the one patient evaluated after 6 months. Last but not least, it may be that the choice to include only adolescent and adult people in our study and to exclude prepuberal children may have affected the efficacy of the treatment. Bone formation activity usually has its highest peak during puberty, and our postpuberal patient population may therefore have more restricted bone formation capacity per se. In addition, the cleft defects in our patients were mostly rather large, thus reducing the likeliness of effective bone regeneration as well.

To our knowledge, this study is the first clinical trial to investigate the safety and feasibility of polyP, either as $\mathrm{Ca}$ polyP MPs alone or in combination with $\mathrm{BCP}$ in humans. A histological examination of the bone at six months was not performed due to the COVID 19 restrictions in Indonesia, which hampered osteoinductivity assessment considerably. We could now only evaluate this aspect based on the radiographic results.

Despite this limitation, since we have now performed video/phone calls at 1 year postoperative, and all patients did report that they had no adverse events and that they were content with the treatment, we can deduce that the treatment with polyP-containing grafts may be safe and in combination with BCP appears to be feasible for alveolar cleft repair. Nevertheless, new studies with a larger group of patients, biopsy evaluations, and suitable polyP formulations encompassing appropriate carriers such as $\mathrm{BCPs}$ or polymeric scaffold materials are required for sound conclusions about their regenerative capacities. Eruption of the teeth through the site, periodontal and health of the root surface of the adjacent teeth, orthodontic movement of adjacent teeth to the grafted site need to be taken into account as well.

\section{Conclusions}

Despite the small sample group size and some missing data points due to the COVID-19 pandemic, we were able to conclude that Ca-polyP MPs and the Ca-polyP $\mathrm{MP} / \mathrm{BCP}$ composites appear to be safe graft materials, however, Ca-polyP MPs alone may not be a sufficiently stable defect-filling scaffold to be used in alveolar cleft repair.

\section{Abbreviations \\ PolyP: Polyphosphate; Ca-polyP MPs: Calcium polyP microparticles; BCP: biphasic calcium phosphate; CLP: Cleft lip and palate; ABG: Alveolar bone grafting; HA: Hydroxyapatite.}

\section{Acknowledgements}

Not applicable.

\section{Authors' contributions}

Alkaabi SA and Natsir Kalla DS: Main author and conceptualization and writing. Ruslin M: Correspondance. Alsabri GA and Jansen NA: Reviewer and editing. Ruslin M, Fauzi A, and Tajrin A: Surgical procedures. Müller WEG, Schröder HC and Wang XG: PolyP Inventor. Forouzanfar T and Helder MN: Methodology and supervision. The authors read and approved the final manuscript.

\section{Authors' information}

Alkaabi SA, Natsir Kalla DS, Alsabri GA, Jansen NA, Forouzanfar T\& Helder MN: Dept. of Oral and Maxillofacial Surgery/Oral Pathology, Amsterdam University Medical Centers and Academic Centre for Dentistry Amsterdam (ACTA), Vrije Universiteit Amsterdam, Amsterdam Movement Sciences, Amsterdam, The Netherlands.

Ruslin M, Fauzi A \& Tajrin A: Dept. of Oral and Maxillofacial Surgery, Faculty of Dentistry, Hasanuddin University, Makassar, Indonesia. Role: Surgical procedures. Müller WEG, Schröder HC, and Wang XG: Institut für Physiologische Chemie, Angewandte Molekularbiologie, Universitätsmedizin, Johannes Gutenberg-Universität Mainz, Mainz, Germany.

\section{Funding}

WEGM and HCS are owners of NanotecMARIN GmbH, Mainz, Germany, and the provider to the polyP graft materials for the clinical trial. SAA received a scholarship from the ministry of health of the UAE. DSNK received a scholarship of the LPDP of Indonesia. The remaining authors declare that the research was conducted in the absence of any commercial or financial relationships that could affect the study result or any other potential of interest.

\section{Availability of data and materials}

Availability of data and materials: Original data is stored securely within the Hasanuddin University, Makassar, Indonesia. Scored date and output for analyses are available upon request from the study.

\section{Declarations}

Ethics approval and consent to participate

The trial protocol has been evaluated by the Ethical Committee of Faculty of Medicine, Hasanuddin University, Makassar, Indonesia has approved the trial with code number 1063/UN4.6.4.5.31/PP36/2019.

\section{Consent for publication}

Written informed consent was obtained from the patient for publication of this case report and any accompanying images. A copy of the written consent is available for review by the Editor-in-Chief of this journal.

\section{Competing interests}

This article is free of conflict of interest and no funding was received. 


\section{Author details}

${ }^{1}$ Department of Oral and Maxillofacial Surgery/Oral Pathology, Amsterdam University Medical Centers and Academic Centre for Dentistry Amsterdam (ACTA), Vrije Universiteit Amsterdam, Amsterdam Movement Sciences, Amsterdam, The Netherlands. ${ }^{2}$ Department of Oral and Maxillofacial Surgery, Fujairah Hospital, Ministry of Health, Fujairah, United Arab Emirates. ${ }^{3}$ Department of Biochemistry, Faculty of Medicine, Hasanuddin University, Makassar, Indonesia. ${ }^{4}$ Department of Oral and Maxillofacial Surgery, Faculty of Dentistry, Hasanuddin University, Makassar, Indonesia. ${ }^{5}$ Institute for Physiological Chemistry, University Medical Center, University Mainz, Mainz, Germany. Institute NanotecMARIN GmbH, Mainz, Germany. ${ }^{7}$ Department of Prosthodontic, Faculty of Dentistry, Hasanuddin University, Makassar, Indonesia.

\section{Received: 17 July 2021 Accepted: 28 October 2021}

Published online: 08 November 2021

\section{References}

1. Sulik KK. Caniofacial development. In: Turvey TA, Vig KWL, editors. Facial clefts and craniosynostosis and principles and management. Philadelphia: WB Saunders Company; 1996. p. 3-27.

2. Seifeldin SA. Is alveolar cleft reconstruction still controversial? (Review of literature). Saudi Dent J. 2016:28(1):3-11.

3. Cho-Lee GY, García-Díez EM, Nunes RA, Martí-Pagès C, Sieira-Gil R, RiveraBaró A. Ann. Review of secondary alveolar cleft repair. Maxillofac Surg. 2013;3(1):46-50.

4. Abyholm FE, Bergland O, Semb G. Secondary bone grafting of alveolar clefts. A surgical/orthodontic treatment enabling a non-prosthodontic rehabilitation in cleft lip and palate patients. Scand. J. Plast. Reconstr Surg. 1981;15:127-40.

5. Rawashdeh MA, Telfah $\mathrm{H}$. Secondary alveolar bone grafting: the dilemma of donor site selection and morbidity. Br J Oral Maxillofac Surg. 2008;46:665-70

6. Sakamoto Y, Sakamoto T, Ishii T, Kishi K. Assessment of bioabsorbable hydroxyapatite for secondary bone grafting in unilateral alveolar clefts. Cleft Palate Craniofac J. 2020;57(1):114-7.

7. Al-hamady HH, Abd Elazeem AF, Bellah Ahmed NE, Shawkat WM, Elmasry $M$, Abdelrahman MA, et al. Combining autologous bone marrow mononuclear cells seeded on collagen sponge with nano hydroxyapatite, and platelet-rich fibrin: reporting a novel strategy for alveolar cleft bone regeneration. J Craniomaxillofac Surg. 2018;46(9):1593-600.

8. Du F, Wu H, Li H, Cai L, Wang Q, Liu X, Xiao R, Yin N, Cao Y. Bone marrow mononuclear cells combined with beta-tricalcium phosphate granules for alveolar cleft repair: A 12-Month Clinical Study. Sci Rep. 2017 :23;7(1):13773.

9. Sadove AM, Nelson CL, Eppley BL, Nguyen B. An evaluation of calvarial and iliac donor sites in alveolar cleft grafting. Cleft Palate $J$. 1990;27(3):225-8.

10. Müller WEG, Achermann M, Wang $S$, Neufurth M, Muñoz-Espi R, et al. Inorganic polyphosphate induces accelerated tube formation of HUVEC endothelial cells. Cell. Mol. Life Sci. 2013;75:21-32.

11. Müller WEG, Neufurth M, Wang S, Ackermann M, Muñoz-Espí R, et al. Amorphous, smart, and bioinspired polyphosphate nano/microparticles: a biomaterial for regeneration and repair of osteo-articular impairments in-situ. Int J Mol Sci. 2018; 31:19(2).

12. Müller WEG, Wang XH, Diehl-Seifert B, Kropf K, Schloßmacher $U$, et al. Inorganic polymeric phosphate/polyphosphate as an inducer of alkaline phosphatase and a modulator of intracellular Ca2+ level in osteoblasts (SaOS- 2 cells) in vitro. Acta Biomater. 2011;7:2661-71.

13. Wang XH, Schröder HC, Müller WEG. Amorphous polyphosphate, a smart bioinspired nano-/bio-material for bone and cartilage regeneration: towards a new paradigm in tissue engineering. J. Mat Chem B. 2018;6:2385-412.

14. Wang XH, Schröder HC, Wiens M, Ushijima H, Müller WEG. Bio-silica and bio-polyphosphate: applications in biomedicine (bone formation). Curr Opin Biotechnol. 2012;23:570-8.

15. Müller WE, Schröder HC, Tolba E, Diehl-Seifert B, Wang X. Mineralization of bone-related SaOS-2 cells under physiological hypoxic conditions. FEBJ. 2016;283(1):74-87.

16. Habibovic P, Yuan H, Van der Valk CM, Meijer G, Van Blitterswijk CA, et al. 3D microenvironment as essential element for osteoinduction by biomaterials. Biomaterials. 2015;26(17):3565-75.

17. Yuan H, Yang Z, De Bruijn JD, De Groot K, Zhang X. Material-dependent bone induction by calcium phosphate ceramics: a 2.5-year study in dogs. Biomaterials. 2011;22(19):2617-23.

18. Miron RJ, Sculean A, Shuang Y, Bosshardt DD, Gruber R, Buser D, et al. Osteoinductive potential of a novel biphasic calcium phosphate bone graft in comparison with autographs, xenografts, and DFDBA. Clin Oral Implants Res. 2016;27(6):668-75.

19. Manjubala I, Sastry TP, Kumar RV. Bone in-growth induced by biphasic calcium phosphate ceramic in femoral defect of dogs. J Biomater Appl. 2005;19(4):341-60.

20. Bergland O, Semb G, Abyholm F, Borchgrevink H, Eskeland G. Secondary bone grafting and orthodontic treatmentin patients with bilateral complete clefts of lip and palate. Annals of Plastic Surgery. 1986;17:460-74.

21. Kawakami S, Hiura K, Yokozeki M, Seike T, Nakanishi H, Moriyama K. Prognostic implications of nasal cavity and cleft morphology in secondary bone grafting. Cleft Palate Craniofac J. 2002;39:575-81.

22. Prins HJ, Schulten EA, Ten Bruggenkate CM, Klein-Nulend J, Helder MN. Bone regeneration using the freshly isolated autologous stromal vascular fraction of adipose tissue in combination with calcium phosphate ceramics. Stem Cells Transl.Med. 2016;5(10):1362-74.

23. Semb G. Effects of alveolar bone grafting on maxillary growth in unilateral cleft lip and palate patients. Cleft Palate J. 1988;25:288-95.

24. Müller WEG, Tolba E, Schröder HC, Neufurth M, Wang S, Link T, Al-Nawas B, Wang $\mathrm{XH}$. A new printable and durable N, O-carboxymethyl chitosanCa2+-polyphosphate complex with morphogenetic activity. J Mat Chem B. 2015;3:1722-30.

25. Wang XH, Wang S, He, Tolba E, Schröder HC, Diehl-Seifert B, Müller WEG. Polyphosphate as a Bioactive and Biodegradable Implant Material: Induction of Bone Regeneration in Rats . Adv Eng Materials. 2016:8:1406-1417.

26. De Ruiter A, Janssen N, van Es R, Frank M, Meijer G, Koole R, et al. Microstructured beta-tricalcium phosphate for repair of the alveolar cleft in cleft lip and palate patients: a pilot study. Cleft Palate Craniofac J. 2015;52(3):336-40.

27. Witherow H, Cox S, Jones E, Carr R, Waterhouse N. A new scale to assess radiographic success of secondary alveolar bone grafts. Cleft Palate J. 2002:39:255-60.

\section{Publisher's Note}

Springer Nature remains neutral with regard to jurisdictional claims in published maps and institutional affiliations. 